Article

\title{
Thulium-Doped Silica Fibers with Enhanced Fluorescence Lifetime and Their Application in Ultrafast Fiber Lasers
}

\author{
Jakub Cajzl 1,*(D), Pavel Peterka ${ }^{1}$, Maciej Kowalczyk ${ }^{2}$, Jan Tarka ${ }^{2}$, Grzegorz Sobon ${ }^{2}$, \\ Jaroslaw Sotor $^{2}$, Jan Aubrecht ${ }^{1} \mathbb{D}$, Pavel Honzátko ${ }^{1} \mathbb{D}$ and Ivan Kašík ${ }^{1}$ \\ 1 Institute of Photonics and Electronics of the Czech Academy of Sciences, 18251 Prague, Czech Republic; \\ peterka@ufe.cz (P.P.); aubrechtj@ufe.cz (J.A.); honzatko@ufe.cz (P.H.); kasik@ufe.cz (I.K.) \\ 2 Laser \& Fiber Electronics Group, Wroclaw University of Technology, Wybrzeze Wyspianskiego 27, \\ 50-370 Wroclaw, Poland; m.kowalczyk@pwr.edu.pl (M.K.); jan.tarka@pwr.edu.pl (J.T.); \\ grzegorz.sobon@pwr.edu.pl (G.S.); jaroslaw.sotor@pwr.edu.pl (J.S.) \\ * Correspondence: cajzl@ufe.cz; Tel.: +420-266-773-528
}

Received: 22 August 2018; Accepted: 14 September 2018; Published: 16 September 2018

\begin{abstract}
In this work we report on the thulium-doped silica-based optical fibers with increased fluorescence lifetime of the ${ }^{3} \mathrm{~F}_{4}$ level thanks to the modification of the local environment of thulium ions by high content of alumina. The determination of the cross-relaxation energy-transfer coefficients from the measurements of the fluorescence lifetimes of the ${ }^{3} \mathrm{~F}_{4}$ and ${ }^{3} \mathrm{H}_{4}$ energy levels of $\mathrm{Tm}^{3+}$ ions in the experimentally prepared optical fiber is provided as well. Preforms of optical fibers were prepared either by conventional solution-doping of $\mathrm{Tm}^{3+}$ and $\mathrm{Al}^{3+}$ ions or by dispersion-doping of $\mathrm{Tm}^{3+}$ ions with alumina nanoparticles. Optical fibers were characterized by means of $\mathrm{Tm}, \mathrm{Al}$, and Ge concentrations, refractive index profiles, optical spectral absorption and luminescence, and by time-resolved fluorescence spectroscopy. Highly aluminium-codoped thulium silicate optical fibers exhibited fluorescence lifetimes of over $\sim 500 \mu$ s with maximum value of $756 \mu$ s, which means a fluorescence lifetime enhancement when compared to the thulium-doped fibers reported elsewhere. We show an application of the thulium-doped fiber in a compact all-fiber ring laser that is passively mode-locked by using graphene-based saturable absorber. The output pulsewidth and repetition rate were $905 \mathrm{fs}$ and $32.67 \mathrm{MHz}$, respectively.
\end{abstract}

Keywords: thulium; lifetime; cross-relaxation; fiber lasers; energy transfer; optical fibers; ultrafast lasers; silica; Thulium-Doped Fiber Amplifiers (TDFA)

\section{Introduction}

Thulium-doped fiber lasers operate in the region of wavelengths around $2 \mu \mathrm{m}$ and can be used as high-power laser sources. Devices operating in the region of wavelengths around $2 \mu \mathrm{m}$ receive growing attention nowadays because they can be used for so-called "eye-safe" applications, e.g., laser surgery, biological imaging, materials processing, atmospheric transmission, defense, etc. [1]. Thulium-doped fibers are attractive $2 \mu \mathrm{m}$ sources despite the low quantum conversion efficiency (QE) of the first excited energy level ${ }^{3} \mathrm{~F}_{4}$, which is about $10 \%$ compared to $\sim 100 \% \mathrm{QE}$ of the ytterbium- and erbium-doped fibers at around $1 \mu \mathrm{m}$ and $1.5 \mu \mathrm{m}$, respectively [2]. Low QE usually causes shortening of energy storage time and increase of laser threshold. However, the effect on the laser slope efficiency is negligible. Therefore, high-power, continuous-wave (cw) Tm-doped fiber lasers can be built even with active medium of impaired QE efficiency. High QE is required especially in photonic devices such as ASE (Amplified Spontaneous Emission) sources, low- and moderate-average-power fiber lasers and amplifiers, or Q-switched pulsed sources. 
The $\mathrm{QE}$ of the upper laser level ${ }^{3} \mathrm{~F}_{4}$ is proportional to the fluorescence lifetime of this energy level. The measured fluorescence lifetime of ${ }^{3} \mathrm{~F}_{4}$ level in silica-based fibers depends on the core composition [2-10]. Typically, the reported values in thulium-doped silica-based fibers varies between 300 and $450 \mu$ s, e.g., $335 \mu$ s [4], $420 \mu$ s [5], 377-424 $\mu$ s [6]. Much lower lifetime of about $200 \mu$ s in silica fibers prepared by solution doping method was also reported [2,3]. On the other hand, the lifetime can be enhanced with high concentration of modifiers in the core, e.g., up to $590 \mu$ s by Y-codoping and nano-modification [7]. Fluorescence lifetimes of $560 \mu \mathrm{s} \mathrm{in} \mathrm{Ge/Al-silica} \mathrm{fibers} \mathrm{and} 650 \mu$ s were reported in specially optimized Tm-doped fibers but concentrations of co-dopants were not disclosed in the paper [8]. The highest fluorescence lifetime of $950 \mu$ s in silicate fibers prepared by Modified-Chemical Vapor Deposition (MCVD) was reported in thulium-doped fiber with high (24 mol.\%) concentration of $\mathrm{GeO}_{2}$ by chelate method of doping [9].

In this paper we report on the experimental and theoretical characterization of the thulium-doped silica optical fibers with increased QE. The methods of preparation and characterization are reported, especially the method of fluorescence lifetime measurement where systematic error of the lifetime due to amplified spontaneous emission (ASE) effect and cross-relaxation processes was eliminated by extrapolation with decreasing length of the fiber under test and with decreasing excitation power. The cross-relaxation energy-transfer coefficients of Tm ions in the silica glass matrix are estimated based on the fluorescence lifetime measurements. We show an application of one of the thulium-doped fiber samples in a compact all-fiber ring laser that is passively mode-locked by using graphene-based saturable absorber.

\section{Materials and Methods}

\subsection{Preparation of Preforms and Optical Fibers}

Optical fibers were prepared by drawing from preforms manufactured by MCVD (Modified-Chemical Vapor Deposition) method and solution-doping technique [11]. The process of doping started with deposition of the porous silica frit using gaseous $\mathrm{SiCl}_{4}$ under $1550{ }^{\circ} \mathrm{C}$ by $\mathrm{MCVD}$ method on the inner side of silica tube. The frit was afterwards soaked either with an ethanolic solution of $\mathrm{AlCl}_{3}$ and $\mathrm{TmCl}_{3}$, or with an ethanolic suspension of alumina nanoparticles $\left(\mathrm{Al}_{2} \mathrm{O}_{3}, \mathrm{~d}=50 \mathrm{~nm}\right)$ and $\mathrm{TmCl}_{3}$. The ceramic nanoparticle doping extension of the MCVD method was firstly reported at 20th Annual Meeting of the IEEE Lasers and Electro-Optics Society in 2007 [12], and now it is well accepted as a method that allows improvement and tailoring of spectral properties of active optical fibers [13-16]. After the soaking and drying of the frit, the doped silica tubes were sintered at temperatures from $1000{ }^{\circ} \mathrm{C}$ to $1850{ }^{\circ} \mathrm{C}$ and collapsed under heat at $1900-2220^{\circ} \mathrm{C}$ to the final preforms. Finally, optical fibers with the diameter of $125 \mu \mathrm{m}$ were drawn from the preforms and covered with a UV-curable acrylate.

\subsection{Characterization Methods}

Refractive index profiles (RIPs) of the prepared preforms were measured on the Photon Kinetics's A2600 (Photon Kinetics, Beaverton, OR, USA) refractive index preform analyzer. Concentration profiles of thulium, $\mathrm{GeO}_{2}$, and $\mathrm{Al}_{2} \mathrm{O}_{3}$ in the preforms were determined by the EPMA (Electron Probe Micronalysis) with the Cameca SX-100 electron microprobe (CAMECA, Gennevilliers, France). Optical attenuations (absorptions) were measured using ANDO AQ-1425 optical spectrum analyzer (380-1600 nm) (Yokogawa, Tokyo, Japan) and Fourier-transform infrared (FTIR) spectrometer Nicolet 8700 (1000-2500 nm) (Nicolet CZ, Prague, Czech Republic) together with a halogen lamp as an excitation source.

Fluorescence decay measurements and fluorescence lifetime evaluation were based on our previous experience in this field [17,18]. Fluorescence decays for the fluorescence lifetime evaluation were recorded by detection of the fluorescence either directly from the optical fiber core with the use of the wavelength-division multiplexer (WDM) (i.e., longitudinal-direction detection setup), or 
from the side perpendicular to the stripped optical fiber (i.e., side detection setup). The setups for the fluorescence lifetime measurements are shown in the Figure 1. The side-detection setup has the advantage in that it largely suppresses unwanted influence of the ASE (Amplified Spontaneous Emission) on the fluorescence decay duration and there is no need of the WDM. On the contrary, the advantage of the detection from longitudinal direction is that even weak fluorescence signals can be processed, e.g., in the case of low rare-earth doping concentrations, narrow-fiber core, or low-sensitivity of the detector. The side-detection from bare optical fiber was done in close proximity to the splice with the pigtail. Fluorescence lifetime measurements using the first and second experimental arrangements (Figure 1a,b, respectively) were done using ThorLabs FPL1054S laser (Thorlabs, Newton, NJ, USA) diode operating at $1619 \mathrm{~nm}$ and max. An $88 \mathrm{~mW}$ output power as the excitation source, ILX Lightwave 3900 with LCM-39437 (ILX Lightwave, Bozeman, MT, USA) module as laser diode and thermoelectric cooler (TEC) power source, Agilent 33512B (Agilent Technologies, Santa Clara, CA, USA) for waveform generation to modulate power source, in-house-built optical detector based on a Hamamatsu G8372-01 InGaAs PIN Photodiode (0.9-2.1 $\mu \mathrm{m})$ (Hamamatsu Photonics, Hamamatsu City, Japan), Teledyne Lecroy HDO6034 (Teledyne LeCroy, Chestnut Ridge, NY, USA) 350 MHz oscilloscope with used averaging of 2000 sweeps, and computer for data acquisition. In the setup the L-band optical isolator (central wavelength $1580 \mathrm{~nm}$ ) and specially designed and manufactured WDM for the separation of pump at $1610 \mathrm{~nm}$ and signal at around $2 \mu \mathrm{m}$ were utilised [19]. The total response time of the system was measured to be around $2 \mu \mathrm{s}$, which is sufficiently short response time to measure lifetimes of the order of several hundreds of microseconds (a general rule of thumb is to have the total response time of the system lower than $1 / 10$ or better $1 / 20$ of the measured lifetime).

(a)

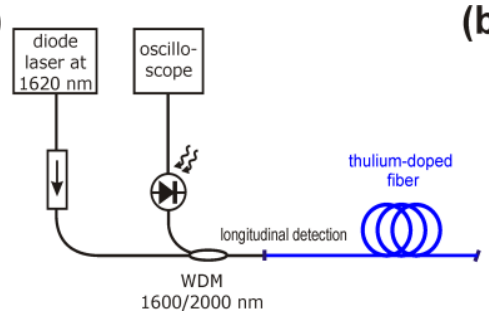

(b)

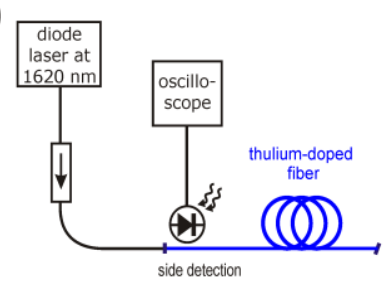

(c)

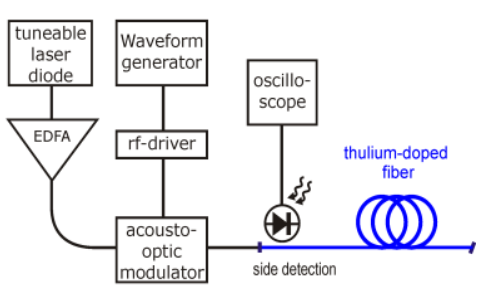

Figure 1. Fluorescence lifetime measurement setups: (a) detection in longitudinal direction via wavelength-division multiplexer (WDM), (b) side detection using modulated pump laser diode, (c) side detection using high-power EDFA and acousto-optic modulator.

Measurements done using the third experimental setup (Figure 1c) were carried out with the Agilent 8164A (Already stated) laser operating at $1565 \mathrm{~nm}$ as excitation source, Keopsys 5W EDFA (Keopsys, Lannion, France) as optical amplifier, Gooch \& Housego A109 (Gooch \& Housego, Ilminster, UK) as an acousto-optic modulator (AOM), Gooch \& Housego radio-frequency AOM driver, ThorLabs PDA10D-EC (1.2-2.6 $\mu \mathrm{m}$ ) optical detector (Already stated), and Agilent DSO-X 2024A oscilloscope (Already stated) with waveform generator to control the AOM driver, and computer for data acquisition; oscilloscope was operated with averaging of 65536 samples. The maximum used excitation powers were $75 \mathrm{~mW}$ for the ThorLabs FPL1054S (Already stated) (first and second setup arrangement) and $500 \mathrm{~mW}$ for the Agilent 8164A (Already stated) with Keopsys 5W EDFA (Already stated) (third setup arrangement).

Additionally, the measurement of lifetime of ${ }^{3} \mathrm{H}_{4}$ energy level of Tm ions at the wavelength of $793 \mathrm{~nm}$ was done. We have also used a variable attenuator EXFO FVA-3100 (EXFO, Quebec City, $\mathrm{QC}$, Canada) for the possibility to reach even lower pump powers and therefore for achieving better extrapolation results during the evaluation of lifetime. For the measurement of the ${ }^{3} \mathrm{H}_{4}$ energy level the Lumics LU0793M250 (Lumics, Berlin, Germany) laser diode (793 nm, $250 \mathrm{~mW}$ ) and Si-based detector were used.

Great attention was given on the elimination of the ASE effect in the fluorescence decay measurements by the use of the technique of extrapolation from various pump powers and fiber 
lengths of the measured optical fiber. The technique was verified on Er-doped optical fiber with known characteristics and preliminary results were presented in a conference paper [18]. Fluorescence lifetimes were measured with several lengths of optical fibers (by cut-back method) and with different pump powers up to $500 \mathrm{~mW}$. The study of the shortening of the fluorescence lifetime (with increasing pump power) is helping us with the characterization of the cross-relaxation energy-transfer coefficients of Tm ions in fiber core.

\subsection{Mode-Locked Fiber Laser Setup}

The setup of a mode-locked fiber laser is depicted in Figure 2. As an active fiber a piece of Tm-doped fiber with increased QE was used. The laser is pumped by the Er/Yb-doubled clad fiber amplifier seeded by the $1560 \mathrm{~nm}$ laser diode connected through 1560/2000 WDM. The signal was coupled out the resonator using 30\% output coupler. The fiber-based in-line polarization controller allows to adjust the intra-cavity polarization and to start the mode-locked operation while the fiber isolator forced unidirectional signal propagation. The total cavity length with the $98 \mathrm{~cm}$ long piece of active fiber is approximately $6.25 \mathrm{~m}$ which corresponds to repetition frequency of $\sim 32.6 \mathrm{MHz}$. In order to investigate influence of the active fiber length on the laser performance, the Tm-doped fiber was subsequently shortened (without any change in the repetition rate, thanks to lengthening of the passive fiber). The detailed laser parameters are described in Section 3.3. Such designed laser cavity was passively mode-locked using a saturable absorber based on graphene/PMMA (poly methyl methacrylate) composite containing 24 layers of graphene. Its nonlinear optical parameters such as modulation depth, non-saturable losses, and saturation fluence (measured at $1550 \mathrm{~nm}$ ) were at the level of $5.5 \%, 374 \%$, and $180 \mu \mathrm{J} / \mathrm{cm}^{2}$, respectively. The full information on the graphene saturable absorber manufacturing technology and methods of its nonlinear properties measurement were presented in previous works [20-22].

The performance of the laser was determined using the optical spectrum analyzer (Yokogawa AQ6370B) (Yokogawa, Tokyo, Japan), radio frequency (RF) spectrum analyzer (Agilent EXA N9010A) (Already stated) connected to a photodiode (Discovery Semiconductors DSC2-50S) and autocorrelator (Femtochrome FR-103XL) (Discovery Semiconductors, Ewing, NJ, USA).

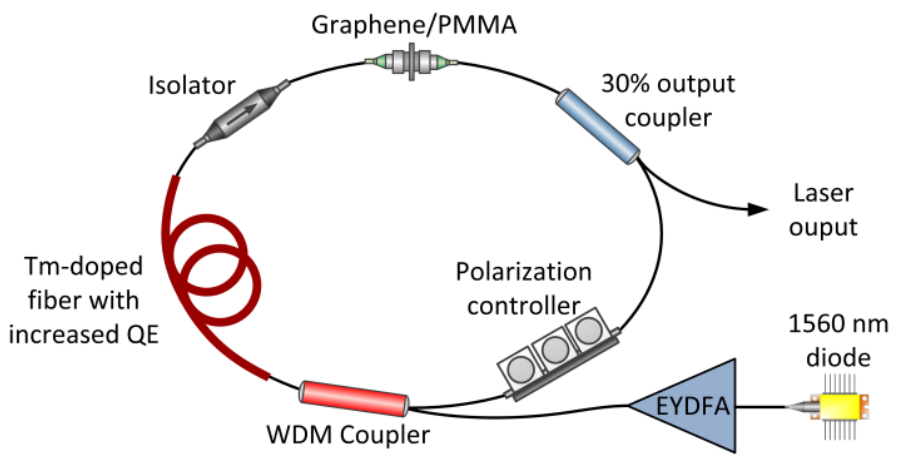

Figure 2. The setup of a Tm-doped, mode-locked fiber laser based on graphene saturable absorber.

\subsection{Theoretical Evaluation of Energy-Transfer Coefficients}

In order to better understand the influence of the Tm doping concentration levels on the resulting time-dependent fluorescence properties, the theoretical calculation of cross-relaxation energy-transfer coefficients of Tm ions in the silica glass matrix together with the fluorescence lifetime characterization were studied. The basic theoretical estimation of energy transfer (cross-relaxation) coefficients for the selected optical fiber denoted as SD (solution doping) in this text was done in our previous study as a contribution on the conference Photonics Prague, 28-30 August 2017, Prague, Czech Republic [23]. In this article we briefly summarize the theoretical model and the results of theoretical evaluation of cross-relaxation coefficients. The basic diagram of energy levels of Tm ions is shown 
in the Figure 3. In our model we studied the cross-relaxation energy-transfer coefficients describing the transitions between the energy levels ${ }^{3} \mathrm{H}_{4},{ }^{3} \mathrm{~F}_{4}$ and ${ }^{3} \mathrm{H}_{6}$ of $\mathrm{Tm}$ ions in optical fiber core. The cross-relaxation energy-transfer processes considered were $\left({ }^{3} \mathrm{H}_{4},{ }^{3} \mathrm{H}_{6}\right) \rightarrow\left({ }^{3} \mathrm{~F}_{4},{ }^{3} \mathrm{~F}_{4}\right)$ ruled by the energy transfer coefficient $k_{3011}$ and energy transfer up-conversion process $\left({ }^{3} \mathrm{~F}_{4},{ }^{3} \mathrm{~F}_{4}\right) \rightarrow\left({ }^{3} \mathrm{H}_{4},{ }^{3} \mathrm{H}_{6}\right)$ ruled by the energy transfer coefficient $k_{1130}$. Both involved processes are labeled as $C R_{30 \leftrightarrow 11}$. The procedure of calculating the approximate values of the two coefficients is described step-by-step in [23].

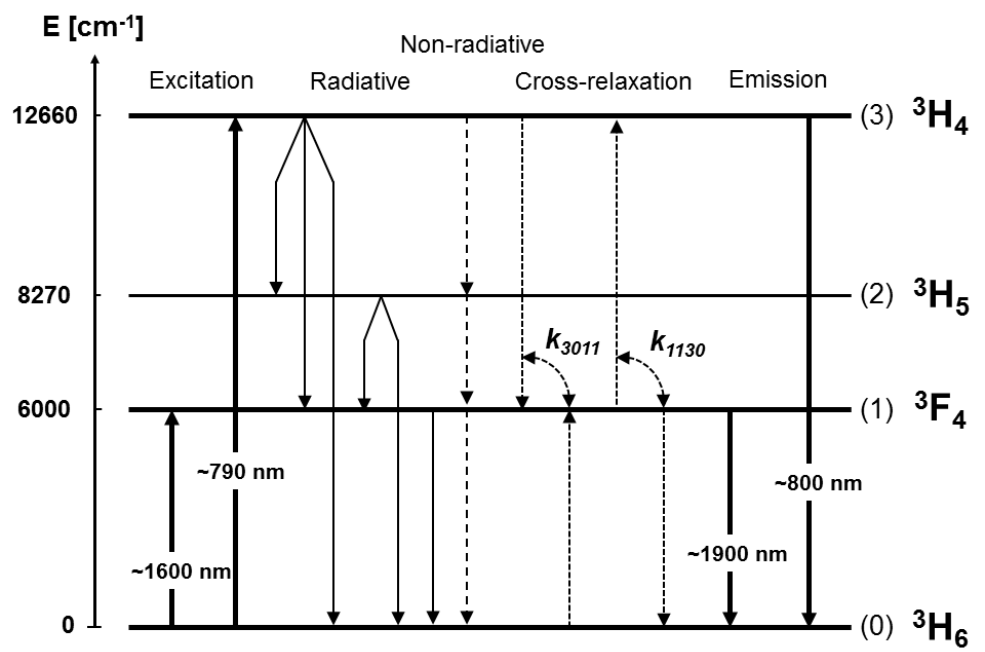

Figure 3. Energy levels of $\mathrm{Tm}^{3+}$ ion including possible energy transitions between energy levels with the indication of cross-relaxation energy-transfer coefficients. The numbers in the arrows in the diagram are the wavelengths (in nanometers) of the corresponding transitions [23].

The basic set of rate equations used for the theoretical model with the lowest 4 energetic states ${ }^{3} \mathrm{H}_{6}$ (level 0), ${ }^{3} \mathrm{~F}_{4}$ (level 1), ${ }^{3} \mathrm{H}_{5}$ (level 2), and ${ }^{3} \mathrm{H}_{4}$ (level 3) is derived from Eichhorn et al. [24], Jackson et al. [4], and Peterka et al. [25] and the equations are having the following form:

$$
\begin{gathered}
\frac{d N_{0}}{d t}=\left(R_{30} N_{3}+R_{20} N_{2}+R_{10} N_{1}\right)+\left(W_{30} N_{3}+W_{10} N_{1}-W_{03} N_{0}-W_{01} N_{0}\right)-C R_{30 \leftrightarrow 11}-C R_{20 \leftrightarrow 11} \\
\frac{d N_{1}}{d t}=\left(R_{31} N_{3}+R_{21} N_{2}-R_{10} N_{1}\right)+\left(W_{01} N_{0}-W_{10} N_{1}\right)+2 \cdot C R_{30 \leftrightarrow 11}+2 \cdot C R_{20 \leftrightarrow 11} \\
\frac{d N_{2}}{d t}=\left(R_{32} N_{3}-R_{21} N_{2}-R_{20} N_{2}\right)-C R_{20 \leftrightarrow 11} \\
\frac{d N_{3}}{d t}=\left(-R_{32} N_{3}-R_{31} N_{3}-R_{30} N_{3}\right)+\left(W_{03} N_{0}-W_{30} N_{3}\right)-C R_{30 \leftrightarrow 11}
\end{gathered}
$$

where $N_{i}$ is a population density of energy level $i, t$ is a time, $R_{i j}$ describes the kinetics of the transition between levels $i$ and $j$ (including non-radiative process of multiphonon quenching), $W_{i j}$ is a probability of light-induced transition between levels $i$ and $j$ for the pump or signal intensity, and $C R_{i j \leftrightarrow l m}$ is the cross-relaxation term for the energy transitions between two $\mathrm{Tm}^{3+}$ ions in the energy level states of $i$ and $j$ towards energy level states of $l$ and $m$ (and vice versa). The transition rates $W_{i j}$ and kinetics of the different levels $R_{i j}$ are defined in [24] and are as follows:

$$
\begin{aligned}
& W_{01}=\sigma_{a}\left(\lambda_{s}\right) \cdot \lambda_{s} \cdot \frac{I_{s}^{+}+I_{s}^{-}}{h \cdot c} \\
& W_{10}=\sigma_{e}\left(\lambda_{s}\right) \cdot \lambda_{s} \cdot \frac{I_{s}^{+}+I_{s}^{-}}{h \cdot c} \\
& W_{03}=\sigma_{a}\left(\lambda_{p}\right) \cdot \lambda_{p} \cdot \frac{I_{p}^{+}+I_{p}^{-}}{h \cdot c}
\end{aligned}
$$




$$
\begin{gathered}
W_{30}=\sigma_{e}\left(\lambda_{p}\right) \cdot \lambda_{p} \cdot \frac{I_{p}^{+}+I_{p}^{-}}{h \cdot c} \\
R_{10}=\frac{1}{\tau_{s p, 10}}+\frac{1}{\tau_{r, 10}} \\
R_{20}=\frac{1}{\tau_{s p, 20}} \\
R_{21}=\frac{1}{\tau_{s p, 21}}+\frac{1}{\tau_{r, 21}} \\
R_{30}=\frac{1}{\tau_{s p, 30}} \\
R_{31}=\frac{1}{\tau_{s p, 31}} \\
R_{32}=\frac{1}{\tau_{s p, 32}}+\frac{1}{\tau_{r, 32}}
\end{gathered}
$$

where $\sigma_{a}$ and $\sigma_{e}$ are absorption and emission cross-sections, respectively; $\lambda_{p}$ and $\lambda_{s}$ are pump (p) and signal (s) central wavelengths, respectively; $I_{p}{ }^{+}$and $I_{s}{ }^{-}$are intensities of pump (p) and signal (s), respectively, where + and - are indicating forward and backward propagation of light; $h$ is a Planck constant; $c$ is a speed of light; $\tau_{s p, i j}$ and $\tau_{r, i j}$ are spontaneous and radiative lifetimes (of transitions between energy levels $i$ and $j$ ), respectively. For further details about above mentioned parameters we refer the reader to [24].

The cross-relaxation terms are as follows [24]:

$$
\begin{aligned}
& C R_{30 \leftrightarrow 11}=k_{3011} N_{3} N_{0}-k_{1130} N_{1}^{2} \\
& C R_{20 \leftrightarrow 11}=k_{2011} N_{2} N_{0}-k_{1120} N_{1}^{2}
\end{aligned}
$$

In our model we consider the luminescence with the following assumptions:

1. Only three energy levels ${ }^{3} \mathrm{H}_{6}$ (level 0$),{ }^{3} \mathrm{~F}_{4}$ (level 1) and ${ }^{3} \mathrm{H}_{4}$ (level 3) are considered, because the energy level ${ }^{3} \mathrm{H}_{5}$ (level 2) is having very fast non-radiative multi-phonon transition to the energy level ${ }^{3} \mathrm{~F}_{4}(1)$. Therefore, also the cross-relaxation process $C R_{20 \leftrightarrow 11}$ is neglected.

2. Since we study only the decay part of the fluorescence, we neglect light-induced transitions described by $W_{i j}$ rates.

3. The ASE (Amplified Spontaneous Emission) effect is neglected.

The resulting set of equations under the aforementioned approximations the luminescence of the energy levels 0,1 , and 3 is as follows:

$$
\begin{gathered}
\frac{d N_{0}}{d t}=R_{30} N_{3}+R_{10} N_{1}-C R_{30 \leftrightarrow 11} \\
\frac{d N_{1}}{d t}=R_{31} N_{3}-R_{10} N_{1}+2 \cdot C R_{30 \leftrightarrow 11} \\
\frac{d N_{3}}{d t}=-R_{31} N_{3}-R_{30} N_{3}-C R_{30 \leftrightarrow 11}
\end{gathered}
$$

The resulting final equation used for the calculation of the $k_{3011}$ cross-relaxation coefficient from the transition ${ }^{3} \mathrm{H}_{4} \rightarrow{ }^{3} \mathrm{H}_{6}$ is stated in Equation (20) [24,26-28]. Details of its derivation can be found in [23].

$$
k_{3011}=\frac{1}{N_{0}}\left(\frac{1}{\tau_{3, m}}-\frac{1}{\tau_{3}}\right) \approx \frac{1}{N_{\text {tot }}}\left(\frac{1}{\tau_{3, m}}-\frac{1}{\tau_{3}}\right) \approx \frac{1}{N_{\text {tot }}}\left(\frac{1}{\tau_{3, m}}-\frac{1}{\tau_{3, \text { low }}}\right)
$$


In the calculation of Equation (20) following assumptions were made: due to the low excitation power used for the measurement of the decay rates the ground state population density $N_{0}$ is almost identical to the total population density of all levels $N_{\text {tot }}$ and therefore to the relative $\mathrm{Tm}^{3+}$ concentration; the overall lifetime of the third energy level $\tau_{3}$ is similar to the lifetime of this level in

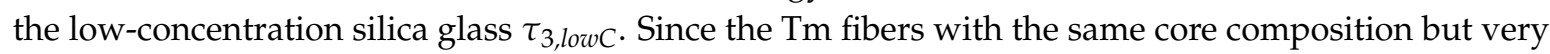
low Tm concentration were not available, we used the value $\tau_{3, \text { low } \mathrm{C}}=58 \mu \mathrm{s}$ measured in a fiber with low Tm concentration and similar core composition with high alumina content [25].

The calculation of cross-relaxation coefficient $k_{1130}$ can be derived from the Equation (21). Since we are considering the decay from the first energy level $\left({ }^{3} \mathrm{~F}_{4}\right)$ to the ground state $\left({ }^{3} \mathrm{H}_{6}\right)$ and the population of the third $\left({ }^{3} \mathrm{H}_{4}\right)$ energy level $N_{3}$ is substantially smaller than that of the first energy level $N_{1}$, we can make an approximation for the Equation (18) that the $N_{3}$ is close to zero and therefore to exclude the terms containing $N_{3}$. After expanding the used parameters $R_{i j}$ and $C R_{30 \leftrightarrow 11}$ in the Equation (18), the equation has the following form:

$$
\frac{d N_{1}}{d t}=-\frac{1}{\tau_{10}} \cdot N_{1}-2 \cdot k_{1130} N_{1}^{2}=-N_{1}\left(\frac{1}{\tau_{1}}+2 \cdot k_{1130} N_{1}\right)=-N_{1} \cdot \frac{1}{\tau_{1, m}}
$$

The coefficient $k_{1130}$ was estimated from the measured fluorescence lifetimes of the ${ }^{3} \mathrm{~F}_{4}$ energy level using the Equation (22). Two limiting cases of measured lifetime were utilised in the evaluation of the coefficient $k_{1130}$-the lifetime under very high pump power $\tau_{1, \text { high }}$ and lifetime under almost zero pump power $\tau_{1, \text { low }}$ (i.e., the value of fluorescence lifetime extrapolated to the "zero" pump power). In the Equation (22) the assumption was made that due to the high excitation power used for the measurement of the $\tau_{1, \text { high }}$ lifetime, the first excited level is almost exclusively populated and therefore $N_{1}$ is similar to the total population $N_{\text {tot }}$ which is equal to the relative concentration of the $\mathrm{Tm}^{3+}$ in the glass core. It should be noted that it is a relatively strong approximation. The $N_{1}$ can only be a fraction of $N_{\text {tot }}$ of about tens of percent. Therefore, the estimated value of $k_{1130}$ should be considered as a lower limit of the possible value. Accordingly, the ratio $\left(k_{1130} / k_{3011}\right)$ is also a lower bound of the estimation. For the case of the "zero" pump power the population of the first energy level $N_{1}$ is very small in comparison with the $N_{0}$ and therefore also the cross-relaxation part $2 \cdot k_{1130} N_{1}^{2}$ with the square of $N_{1}$ is negligible and we can therefore take $\tau_{1, \text { low }}$ for the Equation (22) as an approximated value of the overall lifetime for the first energy level $\tau_{1}$.

$$
k_{1130}=\frac{1}{2 \cdot N_{1}}\left(\frac{1}{\tau_{1, \mathrm{~m}}}-\frac{1}{\tau_{1}}\right) \geq \frac{1}{2 \cdot N_{\text {tot }}}\left(\frac{1}{\tau_{1, \text { high }}}-\frac{1}{\tau_{1, \mathrm{low}}}\right)
$$

\section{Results}

In this study, various compositions of optical fiber preforms were analyzed in order to choose appropriate properties for further evaluation of cross-relaxation coefficients of Tm ions as well as for the fabrication of all-fiber ring laser. The properties of prepared optical fibers and preforms are summarized in Table 1 and include glass matrix compositions, refractive index differences (core-cladding), numerical aperture (NA), cutoff, concentrations of selected dopants (including $\mathrm{Tm}^{3+}$ ), and measured values of the ${ }^{3} \mathrm{~F}_{4}$ level fluorescence lifetime. In the table the glass matrix composition components include: $\mathrm{Tm}=\mathrm{Tm}^{3+}, \mathrm{Si}=\mathrm{SiO}_{2}, \mathrm{Al}=\mathrm{Al}_{2} \mathrm{O}_{3}$, and $\mathrm{Ge}=\mathrm{GeO}_{2}$. Optical fiber preforms were prepared either by conventional solution doping from the solution containing aluminium and thulium chlorides-i.e., SD—or by the deposition from the dispersion of alumina nanoparticles and thulium chloride—i.e., NP. In the table the most important parameters to compare were the value of fluorescence lifetime which is playing crucial role in the function of laser. Other aspects were the background attenuation of the optical fiber as well as the absorption of the thulium ions in the fiber, which are discussed further in the text. 
Table 1. Summary of the properties of the prepared preforms and optical fibers.

\begin{tabular}{|c|c|c|c|c|c|c|c|c|}
\hline Fiber No. & $\begin{array}{c}\text { Preparation } \\
\text { SD/NP }\end{array}$ & Matrix & $\underset{\left(\cdot 10^{-3}\right)}{\Delta \mathrm{n}}$ & $\begin{array}{c}\text { Cutoff } L^{L P_{11}} \\
(\mathrm{~nm})\end{array}$ & $\begin{array}{c}\mathrm{Al}_{2} \mathrm{O}_{3} \\
(\mathrm{~mol} \% \%)\end{array}$ & $\underset{(\mathrm{mol} . \%)}{\mathrm{GeO}_{2}}$ & $\begin{array}{c}\operatorname{Tm}^{3+}(\mathrm{ppm}) \\
\text { AVG }\end{array}$ & $\begin{array}{c}\text { Fluorescence } \\
\text { Lifetime } \\
(\mu \mathrm{s})\end{array}$ \\
\hline SG1365 & SD & Tm-Si & 3.5 & 880 & 0 & 0 & 70 & 220 \\
\hline SG1401 & SD & Tm-Si-Al & 2 & 1900 & 0.33 & 0 & 1740 & 323 \\
\hline SG1360A & SD & Tm-Si-Al & 8 & 1560 & 4.8 & 0 & 2000 & 542 \\
\hline SG1201R & NP & Tm-Si-Al & 27 & 1520 & 11.7 & 0 & 1000 & 756 \\
\hline SG1283 & SD & Tm-Si-Al-Ge & 9.5 & MM & 4.1 & 1.4 & 1140 & 495 \\
\hline SG1290 & SD & Tm-Si-Al-Ge & 10 & 1500 & 4.5 & $\begin{array}{l}1 . x \\
2\end{array}$ & 3000 & 515 \\
\hline SG1361A & SD & Tm-Si-Al-Ge & 7.5 & 1020 & 6 & 7 & 1590 & 500 \\
\hline
\end{tabular}

For the application in optical fiber lasers the most interesting fibers are those with high values of fluorescence lifetime. In the table it can be seen several optical fibers that are interesting in terms of high dopant concentration, high fluorescence lifetime, or both-e.g., SG1364 (highest Tm concentration), SG1201R (highest lifetime), SG1290 (high Tm concentration, high lifetime). However, since the optical fiber SG1364 has a very low fluorescence lifetime of $62 \mu \mathrm{s}$, it is not interesting for the optical fiber lasers. The nanoparticle dispersion-doped optical fiber SG1201R on the other hand was already used in the first rare-earth-doped monolithic fiber laser with FBG inscribed by the deep-UV-femtosecond fiber laser [29]. High alumina content was an advantage for this method of FBG inscription.

For our use we selected an optical fiber SG1290 (labeled as "SD" later in the text) since it exhibited high-dopant concentration of around 3000 ppm-that is advantageous for short-cavity short-pulse lasers-and high fluorescence lifetime of above $0.5 \mathrm{~ms}$; in comparison with the optical fiber SG1201R, the optical fiber SD had a lower background attenuation which is an advantage for the application in all-fiber ring laser. The results of the application are presented in Section 3.3. The details of the selected optical fiber used for the evaluation of the cross-relaxation coefficients of Tm-ions as well as for the fabrication of compact all-fiber ring laser (that is passively mode-locked by using graphene-based saturable absorber) are listed in Table 2. Details of the characterization of the selected optical fiber SD are given in Section 3.1 and 3.2.

Table 2. Basic properties of the selected optical fiber used for the evaluation of the cross-relaxation coefficients of Tm-ions as well as for the fabrication of compact all-fiber ring laser.

\begin{tabular}{cc}
\hline Fiber Label (No.) & Preparation Details \\
\hline SD $(\mathrm{SG} 1290)$ & Conventional solution doping from solution of $1 \mathrm{~mol} \mathrm{~L}^{-1}$ \\
& $\mathrm{AlCl}_{3}$ and $0.04 \mathrm{~mol} \mathrm{~L}{ }^{-1} \mathrm{TmCl}_{3} \cdot 6 \mathrm{H}_{2} \mathrm{O}$ \\
\hline
\end{tabular}

\subsection{Refractive Index and Concentration Profiles, Optical Absorption, and Emission Spectra}

Prepared optical fiber preform of the selected fiber SD was measured for the refractive index profile (RIP) and concentration profiles of core components. The optical fiber RIP and absorption spectrum was measured. The refractive index profile and dopant concentration profiles of prepared optical fiber preform are depicted in Figure 4 with the inset plot of optical fiber's RIP. The optical fiber preform SD had overall $\Delta \mathrm{n}$ of approx. $8 \times 10^{-3}$ r.i.u.; the $\Delta \mathrm{n}$ of the optical fiber was of about $8 \times 10^{-3}$ ri.u. The high value of $\Delta \mathrm{n}$ could be attributed to the direct influence of the content of alumina in the silica matrix [30-32]. The amount of thulium in the preform was of about 0.10 at. \%. 


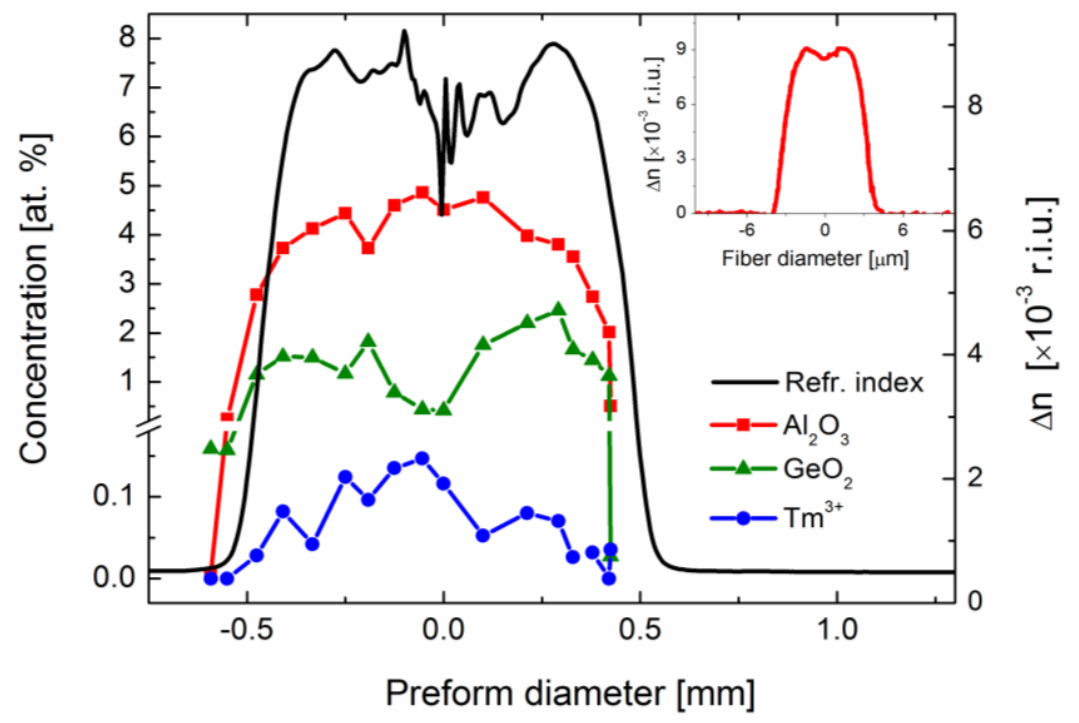

Figure 4. Refractive index profile and dopant concentration profile of prepared optical fiber preform $\mathrm{SD}$ (the inset plot contains the refractive index profile of the optical fiber).

Figure 5a depicts measured optical absorption and emission spectra for the prepared optical fiber SD. Maximum value of absorption was $265 \mathrm{~dB} / \mathrm{m}$ at about $790 \mathrm{~nm}$; absorption of the first excitation level ${ }^{3} \mathrm{~F}_{4}$ of thulium ions at around $1645 \mathrm{~nm}$ was having maximum of around $114 \mathrm{~dB} / \mathrm{m}$ 一the absorption band was spreading from 1470 to $1950 \mathrm{~nm}$. The broad emission band (corresponding to the transition ${ }^{3} \mathrm{~F}_{4} \rightarrow{ }^{3} \mathrm{H}_{6}$ ) spreading from 1530 to $2230 \mathrm{~nm}$ was having maximum at around $1760 \mathrm{~nm}$. Figure $5 \mathrm{~b}$ depicts the original emission spectrum as it was measured on the FTIR spectrometer, together with the spectrum corrected for spectral characteristics of the wideband coupler used in the emission measurement setup as well as corrected for the sensitivity of the detector (extended InGaAs in FTIR spectrometer); the final spectrum (Gaussian multi-peak fit)—with eliminated pump peak at $1611 \mathrm{~nm}$ and dense absorption peaks around $1850 \mathrm{~nm}$ due to the water absorption-is provided as well. It is of a great importance to pay attention on the corrections on any component in the measurement setup (especially the sensitivity of the detector and the spectral characteristics of used components) that are used for the spectral characterization of the prepared samples in order to obtain correct shape of the emission spectra.
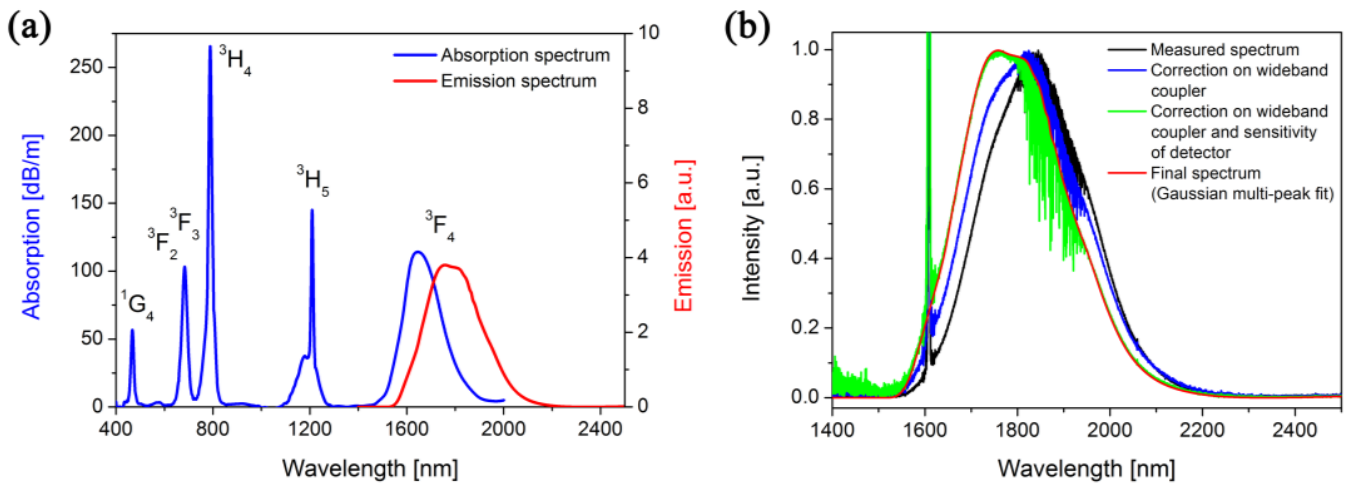

Figure 5. (a) Measured optical absorption and emission spectra of prepared optical fiber SD with the indication of the corresponding absorption and emission energy levels. (b) Optical emission spectrum of optical fiber SD as measured on our FTIR spectrometer together with the spectrum of correction on spectral characteristics of wideband coupler as well as correction on the sensitivity of the detector; also the final spectrum (with eliminated pump peak at $1611 \mathrm{~nm}$ and absorption peaks due to the water absorption) is provided. 


\subsection{Fluorescence Lifetime and Energy-Transfer Coefficients}

The fluorescence lifetime was evaluated from the measured fluorescence decay curves. The evaluation started with the extraction of the decay curve from the oscilloscope output curve- the example measured oscilloscope output for the SD optical fiber is depicted in the Figure 6a. Then the decay curve was normalized from 0 to 1 and the time value in the "1/e" (approximately 0.368) was determined as the lifetime value $\tau$. The fluorescence decay curves in semi-logarithmic scale for different lengths and pump powers with the resulting lifetime values for the SD optical fiber are depicted in the Figure $6 b$.

(a)

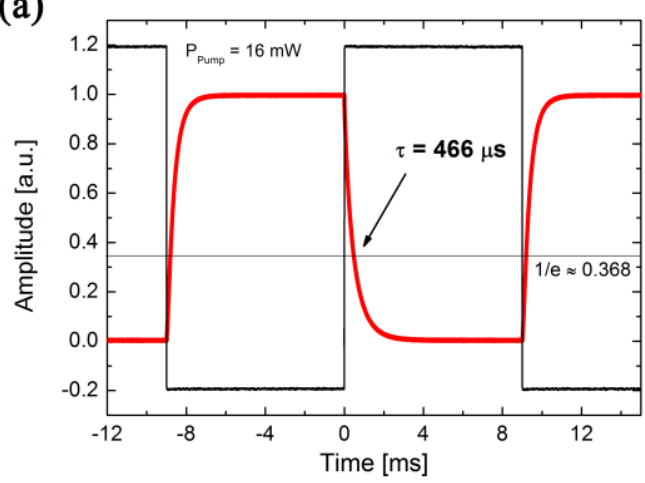

(b)

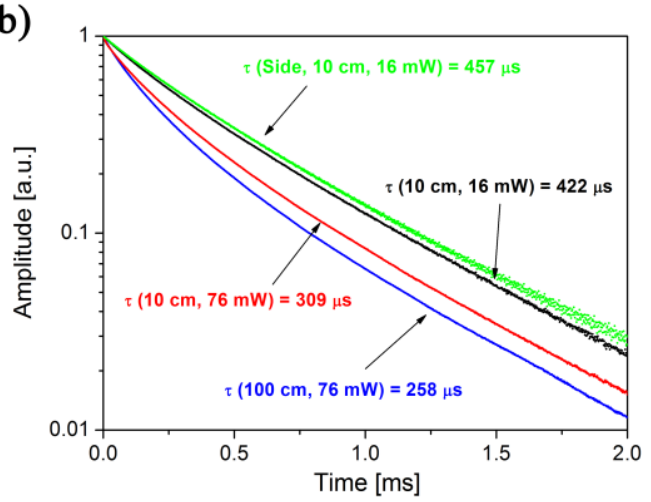

Figure 6. (a) Measured oscilloscope output and (b) fluorescence decay curves for different lengths and pump powers with the resulting lifetime values for the SD optical fiber fiber (green curve-side detection; black, red, and blue curve-longitudinal detection) [23].

In order to eliminate the influence of the ASE effect and energy-transfer processes that are mainly causing the shortening of the fluorescence decay and therefore the lifetime value, we used the method of extrapolation from different optical fiber lengths and pump powers. The extrapolation evaluation is depicted in the Figure 7 for the SD optical fiber. It is able to see that the effect of energy-transfer processes is significant even for the side-detection scheme; it causes deviation as high as $17 \%$, see Figure 7 . The ${ }^{3} \mathrm{~F}_{4}$ fluorescence lifetime of the SD optical fiber was evaluated by extrapolation with the value of $515 \mu \mathrm{s}$.

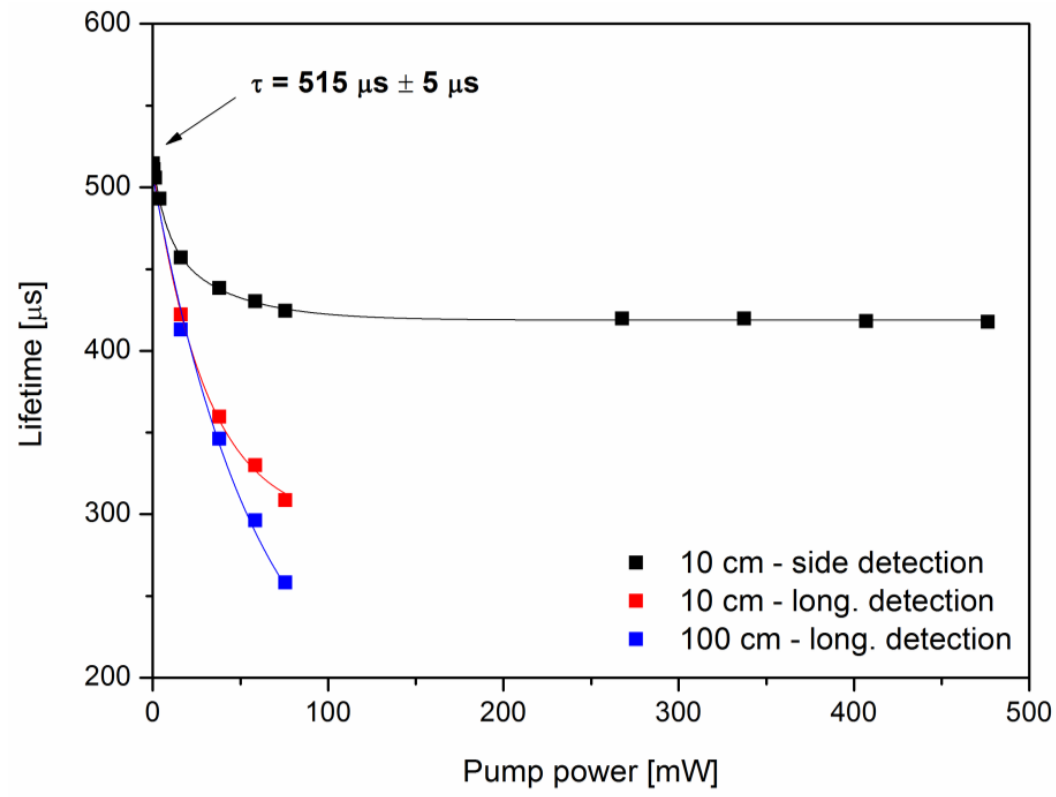

Figure 7. Fluorescence lifetime evaluated by extrapolation from different fiber lengths and pump powers for SD optical fiber in longitudinal- and side-detection arrangements. 
The theoretical estimation of cross-relaxation energy-transfer coefficients $k_{3011}$ and $k_{1130}$ was done by using the Equations (20) and (22), respectively. For the calculation following parameters were taken: measured lifetime values of the ${ }^{3} \mathrm{~F}_{4}$ and ${ }^{3} \mathrm{H}_{4}$ energy levels, lifetime value of ${ }^{3} \mathrm{H}_{4}$ energy level for the low concentration silica glass [25], and the concentration of thulium. All the results including measured and calculated lifetime values and calculated cross-relaxation coefficients are summarized in the Table 3. The ratios between $k_{1130}$ and $k_{3011}$ are 0.014 for the SD optical fiber. This value is of the same order as the value previously reported by Jackson et al. [4] and Eichhorn et al. [24] of $\left(k_{1130} / k_{3011}\right)$ $=0.084$. It should be noted that due to the approximations we made in derivation of Equation (22) the calculated ratio $\left(k_{1130} / k_{3011}\right)$ in Table 3 is the lower bound of the estimation.

Table 3. Tm concentration in the prepared optical fiber, measured and calculated fluorescence lifetime values and calculated cross-relaxation coefficients.

\begin{tabular}{|c|c|c|c|c|c|c|c|}
\hline Fiber & $\begin{array}{c}C\left(\mathrm{Tm}^{3+}\right) \\
\left(\cdot 10^{25} \mathrm{~m}^{-3}\right)\end{array}$ & $\begin{array}{c}\tau\left({ }^{3} F_{4}\right) \text { Low } \\
(\mu \mathrm{s})\end{array}$ & $\begin{array}{c}\tau\left({ }^{3} \mathrm{~F}_{4}\right) \mathrm{High} \\
(\mu \mathrm{s})\end{array}$ & $\begin{array}{c}\tau\left({ }^{3} \mathrm{H}_{4}\right) \\
(\mu \mathrm{s})\end{array}$ & $\begin{array}{c}\tau\left({ }^{3} \mathrm{H}_{4}\right) \text { lowC } \\
(\mu \mathrm{s})\end{array}$ & $\begin{array}{c}k_{3011} \\
\left(\cdot 10^{-22} \mathrm{~m}^{3} / \mathrm{s}\right)\end{array}$ & $\begin{array}{c}k_{1130} \\
\left(\cdot 10^{-24} \mathrm{~m}^{3} / \mathrm{s}\right)\end{array}$ \\
\hline $\begin{array}{c}\text { SD } \\
\text { (SG1290) }\end{array}$ & 6.375 & 515 & 420 & 30 & 58 & 2.52 & 3.44 \\
\hline
\end{tabular}

\subsection{Laser Characteristics}

The mode-locked operation of the laser was obtained when the pump power reached the threshold (Table 4) and the intracavity polarization state was carefully adjusted by the polarization controller. During the experiments the influence of an active fiber length on laser performance was investigated. In the first step, the $98 \mathrm{~cm}$ long Tm-doped fiber was spliced inside the laser cavity. The mode-locked operation was obtained at the $210 \mathrm{~mW}$ pump power level and the soliton pulses manifested themselves by characteristic Kelly sidebands [33,34], see Figure 8a. The solitons were generated in the regime of anomalous average dispersion of the laser resonator. The stable fundamental solitons without any continuous wavelength (CW) components were generated up to the $255 \mathrm{~mW}$ of pump power. For higher pump power the $\mathrm{CW}$ component at optical spectrum was observed as well as the multi-pulses operation. The generated optical solitons with the $4.34 \mathrm{~nm}$ full-width-at-half-maximum (FWHM) were centered at $1939.3 \mathrm{~nm}$ (the measurements were performed at $255 \mathrm{~mW}$ of pump power) and is depicted in Figure 8a (the bottom plot). The correspondent autocorrelation trace presented in Figure $8 \mathrm{~b}$ shows that in this case the generated pulses have duration of $1.034 \mathrm{ps}$. The time bandwidth product (TBP) at the level of 0.36 indicates that they were slightly chirped. The average output power and pulse energy measured at the maximum pump power supporting stable mode-locked operation were $7.5 \mathrm{~mW}$ and 238 pJ, respectively. The RF spectrum (Figure 9a) and the pulse train measured in time domain (Figure $9 \mathrm{~b}$ ) confirms stable operation without any parasitic modulations. The repetition frequency of the laser was $32.67 \mathrm{MHz}$ what corresponds to the $30.6 \mathrm{~ns}$ the subsequent pulse separation. The signal to noise ratio $(\mathrm{S} / \mathrm{N})$ was at the level of $70 \mathrm{~dB}$.

Table 4. Summary of the of the achieved laser parameters.

\begin{tabular}{|c|c|c|c|c|c|c|c|c|c|}
\hline $\begin{array}{c}\text { Tm-Fiber } \\
\text { Length }(\mathrm{cm})\end{array}$ & $\begin{array}{l}P_{\text {th }}{ }^{a} \\
(\mathrm{~mW})\end{array}$ & $\underset{(\mathrm{mW})}{P_{\text {pump_max }} b}$ & $\begin{array}{l}S / N^{c} \\
(d B)\end{array}$ & $\begin{array}{l}\text { FWHM }^{d} \\
(n m)\end{array}$ & $\begin{array}{l}\lambda_{\mathrm{c}} \mathrm{e} \\
(\mathrm{nm})\end{array}$ & $\begin{array}{l}P_{\text {avg }} \mathbf{f} \\
(\mathrm{mW})\end{array}$ & $\begin{array}{l}\mathrm{Eg} \\
(\mathrm{pJ})\end{array}$ & $\begin{array}{l}\tau^{h} \\
\text { (fs) }\end{array}$ & TBP $^{\mathrm{i}}$ \\
\hline 34 & 224 & 242 & 71 & 4.3 & 1886 & 7.3 & 223 & 975 & 0.35 \\
\hline 55 & 196 & 290 & 70 & 4.4 & 1903.5 & 7.8 & 238 & 990 & 0.35 \\
\hline 74 & 208 & 290 & 69 & 5.02 & 1919.8 & 8 & 244 & 905 & 0.37 \\
\hline 98 & 210 & 255 & 70 & 4.34 & 1929.3 & 7.5 & 229 & 1034 & 0.36 \\
\hline
\end{tabular}

${ }^{\mathrm{a}} \mathrm{P}_{\text {th }}$ is the pump power threshold for mode-locked operation. ${ }^{\mathrm{b}} \mathrm{P}_{\text {pump_max }}$ is the maximum pump power at stable mode-locked operation. ${ }^{c} \mathrm{~S} / \mathrm{N}$ is the signal to noise ratio of the RF spectrum. ${ }^{\mathrm{d}} \mathrm{FWHM}$ is the full width at the half maximum of the optical spectrum. ${ }^{\mathrm{e}} \lambda_{\mathrm{c}}$ is the central wavelength of generated solitons. ${ }^{\mathrm{f}} \mathrm{P}_{\mathrm{avg}}$ is the average power. ${ }^{g} \mathrm{E}$ is the pulse energy. ${ }^{\mathrm{h}} \tau$ is the pulse duration. ${ }^{\mathrm{i}} \mathrm{TBP}$ is the time-bandwidth product. 
(a)

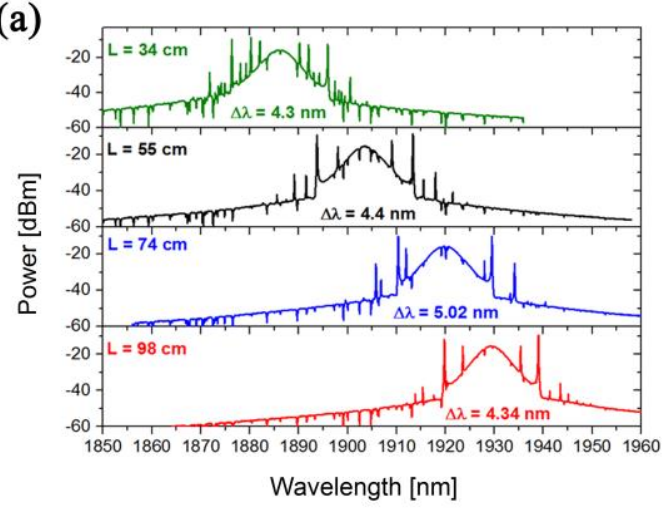

(b)

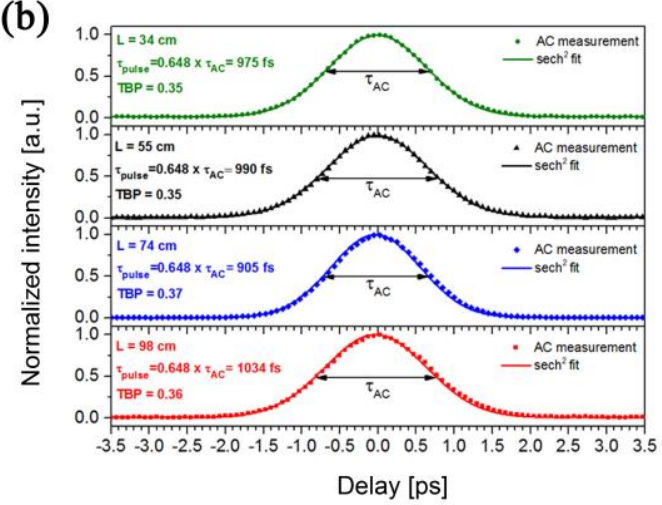

Figure 8. The optical spectra (a) and the autocorrelation traces (b) obtained in laser setups with different length of Tm-doped active optical fiber.

(a)

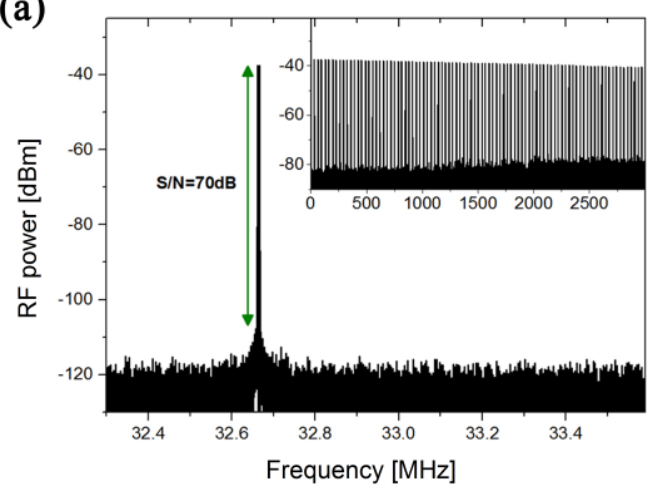

(b)

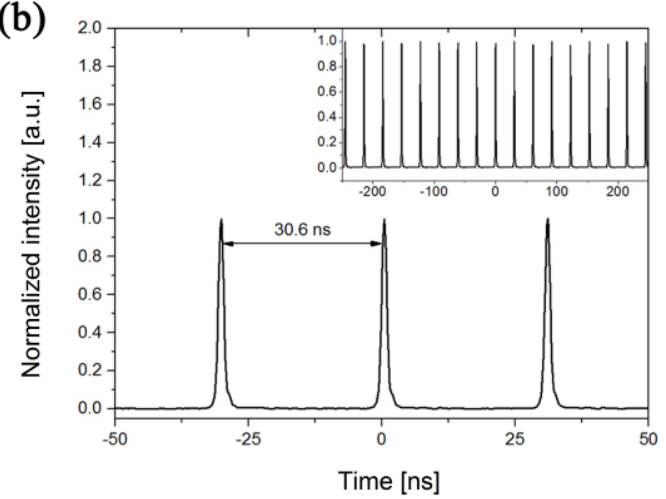

Figure 9. The RF spectrum (a) measured in the $1.3 \mathrm{MHz}$ span with $80 \mathrm{~Hz}$ resolution bandwidth (RBW) presenting the repetition frequency of the laser and the $\mathrm{S} / \mathrm{N}$ ratio-in the inset is the broad range of harmonics without spectral modulations measured in the $3 \mathrm{GHz}$ span with $47 \mathrm{kHz}$ RBW. The oscilloscope trace $(\mathbf{b})$ presenting the train of pulses separated of $30.6 \mathrm{~ns}-$ in the inset is the broad range of pulses confirming stable operation and very low fluctuations of pulse amplitudes.

Subsequently, the length of the active fiber was shortened. The laser setup was fully investigated with the following Tm-doped fiber lengths: $74 \mathrm{~cm}, 55 \mathrm{~cm}$ and $34 \mathrm{~cm}$. In all cases the stable mode-locked operation was obtained (the Tm-doped fiber was further shortened to $20 \mathrm{~cm}$, however the pulse operation was no longer supported). The detailed information on the obtained laser performance are summarized in the Table 4 . The repetition frequency in all investigated setups were $\sim 32.6 \mathrm{MHz}$. In terms of pulse duration and FWHM in all cases the lasers presented similar performances. The pulse durations ranged from 905-990 fs while the FWHM from 4.3-5 nm. The change of the active fiber length did not significantly affect the average output power and the pulse energy because the pump power is almost completely absorbed even in the shorter fiber. Shortening of the active fiber length mostly influenced on the central wavelength of the generated solitons. It was changed from $1929.3 \mathrm{~nm}$ (the $98 \mathrm{~cm}$ long Tm-doped fiber) to $1886 \mathrm{~nm}$ (the $34 \mathrm{~cm}$ long Tm-doped fiber). The change had almost linear character. The central wavelength shifts with fiber length because fiber length influences the average population of thulium ions that are excited to metastable level. For given pump power, the shorter fiber has higher average population inversion than the longer fiber and the spectral gain peak shifts to shorter wavelengths with higher inversion population [35]. Taking into account that the other laser parameters, like pulse duration, average power, and pulse energy are almost not affected by active fiber shortening, this approach can be used as a very simple mechanism of laser wavelength tuning. 


\section{Conclusions}

The characterization of thulium-doped silica optical fibers prepared by solution-doping and by nanoparticles-dispersion-doping has been presented. Dependency of fluorescence lifetime of thulium ions on their local vicinity (matrix modification) was proven. Using nanoparticles-dispersion-doping technique it was possible to achieve high alumina concentration in optical fibers of up to $11.7 \mathrm{~mol} . \%$, which yielded the fluorescence lifetime values of up to $756 \mu$ s. The highest fluorescence lifetime values were obtained for the optical fibers with the glass matrix composition of $\mathrm{SiO}_{2}-\mathrm{Al}_{2} \mathrm{O}_{3}$ (with $\mathrm{Tm}^{3+}$ ions). The shortest fluorescence lifetimes of about $62 \mu$ s and $220 \mu$ s were observed in the optical fibers with $\mathrm{SiO}_{2}-\mathrm{P}_{2} \mathrm{O}_{5}$ and $\mathrm{SiO}_{2}$ glass matrix compositions (with $\mathrm{Tm}^{3+}$ ions), respectively. Addition of germanium in the silica glass matrix caused suppression of the fluorescence lifetime increase (i.e., the increase rate of fluorescence lifetime with increasing alumina concentration was suppressed in germanium-enhanced optical fibers). Further, we have pointed out the importance of the effect of ASE and cross-relaxation processes on the fluorescence lifetime measurement.

We have demonstrated the calculation of the cross-relaxation energy-transfer coefficients for the prepared thulium-doped aluminosilicate optical fiber. From the results of the calculation of the cross-relaxation energy-transfer coefficients in Tm-doped fiber it follows that the ratio between $k_{1130}$ and $k_{3011}$ is in accordance with the values reported previously by other research groups. Our method provides lower estimation of the $k_{1130}$. More precise evaluation of the energy transfer coefficient $k_{3011}$ can be obtained by fitting the measured fluorescence decays with numerical model. The determination of the values of the cross-relaxation coefficients is of very high importance for the accurate modeling of the Tm-doped fiber lasers.

The all-fiber ring laser using the Tm-doped active optical fiber was demonstrated. The ring laser was passively mode-locked by graphene-based saturable absorber. The laser output pulse width, duration, and repetition rate were $5.02 \mathrm{~nm}, 905 \mathrm{fs}$, and $32.67 \mathrm{MHz}$, respectively. The influence of length of active optical fiber on laser performance (central wavelength and pump power) was investigated as well. The central wavelength of developed laser was able to be tuned around $50 \mathrm{~nm}$ wavelength range, i.e., from $1930 \mathrm{~nm}$ to $1886 \mathrm{~nm}$ with the decreasing active fiber lengths from $98 \mathrm{~cm}$ to 34 $\mathrm{cm}$, respectively.

Author Contributions: Conceptualization: J.C., P.P., P.H., and J.S.; Formal Analysis: J.C., P.P., M.K., J.T., and G.S.; Investigation: J.C., P.P., J.A., M.K., J.T., G.S., and I.K.; Methodology: J.C., P.P, M.K., J.T., and G.S.; Validation: J.C., P.P, M.K., J.T., G.S., J.A., and I.K.; Software: J.C. and P.P.; Writing-original draft: J.C., P.P., M.K., J.T., G.S., and J.S.; Funding acquisition: P.P., P.H., I.K., and J.S., Project administration: P.P., P.H., I.K., and J.S.

Funding: This research was funded by the “Grantová Agentura České Republiky” (Czech Science Foundation) under project No. 17-20049S and by the European Action COST MP1401 "Advanced Fibre Laser and Coherent Source as tools for Society, Manufacturing and Lifescience". The work on Tm-doped fiber laser was supported by the "Ministerstwo Nauki i Szkolnictwa Wyższego" (Polish Ministry of Science and Higher Education) under the grant "Ultrashort-pulsed fiber amplifiers for the mid-infrared spectral range" (project No. IP2015 072674).

Acknowledgments: Portions of this work were presented at the symposium Photonics Prague that took place on 28-30 August 2017 in Prague, Czech Republic [23].

Conflicts of Interest: The authors declare no conflict of interest. The funders had no role in the design of the study; in the collection, analyses, or interpretation of data; in the writing of the manuscript, and in the decision to publish the results.

\section{References}

1. Zervas, M.N.; Codemard, C.A. High Power Fiber Lasers: A Review. IEEE J. Sel. Top. Quantum Electron. 2014, 20, 219-241. [CrossRef]

2. Digonnet, M.J.F. Rare Earth Doped Fiber Lasers and Amplifiers; Marcel Dekker: New York, NY, USA, 1993; p. 109.

3. Hanna, D.C.; Percival, R.M.; Smart, R.G.; Tropper, A.C. Efficient and tunable operation of a Tm-doped fibre laser. Opt. Commun. 1990, 75, 283-286. [CrossRef] 
4. Jackson, S.D.; King, T.A. Theoretical modeling of Tm-doped silica fiber lasers. J. Lightwave Technol. 1999, 17, 948-956. [CrossRef]

5. Walsh, B.M.; Barnes, N.P. Comparison of Tm:ZBLAN and Tm:silica fiber lasers; Spectroscopy and tunable pulsed laser operation around $1.9 \mu \mathrm{m}$. Appl. Phys. B 2004, 78, 325-333. [CrossRef]

6. Simpson, D.A.; Gibbs, W.E.; Collins, S.F.; Blanc, W.; Dussardier, B.; Monnom, G.; Peterka, P.; Baxter, G.W. Visible and near infra-red up-conversion in Tm3+/Yb3+ co-doped silica fibers under $980 \mathrm{~nm}$ excitation. Opt. Express 2008, 16, 13781-13799. [CrossRef] [PubMed]

7. Klimentov, D.; Dvoyrin, V.V.; Halder, A.; Paul, M.C.; Das, S.; Bhadra, S.K.; Sorokina, I.T. Emission decay and energy transfer in $\mathrm{Yb} / \mathrm{Tm}$ Y-codoped fibers based on nano-modified glass. Opt. Mater. 2015, 42, 270-275. [CrossRef]

8. Agger, S.D.; Povlsen, J.H. Emission and absorption cross section of thulium doped silica fibers. Opt. Express 2006, 14, 50-57. [CrossRef] [PubMed]

9. Dennis, M.L.; Cole, B. Amplification Device Utilizing Thulium Doped Modified Silicate Optical Fiber. U.S. Patent 6,924,928 B2, 2 August 2005.

10. Gebavi, H.; Taccheo, S.; Milanese, D. The enhanced two micron emission in thulium doped tellurite glasses. Opt. Mater. 2013, 35, 1792-1796. [CrossRef]

11. Kasik, I.; Podrazky, O.; Mrazek, J.; Cajzl, J.; Aubrecht, J.; Probostova, J.; Peterka, P.; Honzatko, P.; Dhar, A. Erbium and $\mathrm{Al}_{2} \mathrm{O}_{3}$ nanocrystals-doped silica optical fibers. Bull. Pol. Acad. Sci.-Tech. Sci. 2014, 62, 641-646. [CrossRef]

12. Podrazky, O.; Kasik, I.; Pospisilova, M.; Matejec, V. Use of alumina nanoparticles for preparation of erbium-doped fibers. In Proceedings of the 20th Annual Meeting of the IEEE Lasers and Electro-Optics Society (LEOS 2007), Lake Buena Vista, FL, USA, 21-25 October 2007; pp. 246-247.

13. Blanc, W.; Dussardier, B.; Monnom, G.; Peretti, R.; Jurdyc, A.M.; Jacquier, B.; Foret, M.; Roberts, A. Erbium emission properties in nanostructured fibers. Appl. Opt. 2009, 48, G119-G124. [CrossRef] [PubMed]

14. Baker, C.C.; Friebele, E.J.; Burdett, A.A.; Rhonehouse, D.L.; Fontana, J.; Kim, W.; Bowman, S.R.; Shaw, L.B.; Sanghera, J.; Zhang, J.; et al. Nanoparticle doping for high power fiber lasers at eye-safer wavelengths. Opt. Express 2017, 25, 13903-13915. [CrossRef] [PubMed]

15. Dhar, A.; Kasik, I.; Podrazky, O.; Matejec, V.; Dussardier, B. Preparation and properties of Er-doped ZrO2 nanocrystalline phase-separated preforms of optical fibers by MCVD process. Int. J. Appl. Ceram. Technol. 2012, 9, 341-348. [CrossRef]

16. Mrázek, J.; Kašík, I.; Procházková, L.; Čuba, V.; Girman, V.; Puchý, V.; Blanc, W.; Peterka, P.; Aubrecht, J.; Cajzl, J.; et al. YAG Ceramic Nanocrystals Implementation into MCVD Technology of Active Optical Fibers. Appl. Sci. 2018, 8, 833. [CrossRef]

17. Cajzl, J.; Peterka, P.; Honzátko, P.; Mrázek, J.; Podrazký, O.; Todorov, F.; Gladkov, P.; Sahu, J.K.; Nunez-Velazquez, M.; Nekvindová, P.; et al. Characterization of fluorescence lifetime of Tm-doped fibers with increased quantum conversion efficiency. Proc. SPIE 2015, 9450, 945017.

18. Peterka, P.; Honzátko, P.; Kašík, I.; Cajzl, J.; Podrazký, O. Thulium-doped optical fibers and components for fiber lasers in $2 \mu \mathrm{m}$ spectral range. Proc. SPIE 2014, 9441, 94410B. [CrossRef]

19. Pisarik, M.; Peterka, P.; Zvanovec, S.; Baravets, Y.; Todorov, F.; Kasik, I.; Honzatko, P. Fused fiber components for "eye-safe" spectral region around $2 \mu \mathrm{m}$. Opt. Quantum Electron. 2014, 46, 603-611. [CrossRef]

20. Sobon, G. Mode-locking of fiber lasers using novel two-dimensional nanomaterials: Graphene and topological insulators [invited]. Photonics Res. 2015, 3, A56-A63. [CrossRef]

21. Krajewska, A.; Pasternak, I.; Sobon, G.; Sotor, J.; Przewloka, A.; Ciuk, T.; Sobieski, J.; Grzonka, J.; Abramski, K.M.; Strupinski, W. Fabrication and applications of multi-layer graphene stack on transparent polymer. Appl. Phys. Lett. 2017, 110, 041901. [CrossRef]

22. Sobon, G.; Sotor, J.; Pasternak, I.; Krajewska, A.; Strupinski, W.; Abramski, K. All-polarization maintaining, graphene-based femtosecond Tm-doped all-fiber laser. Opt. Express 2015, 23, 9339-9346. [CrossRef] [PubMed]

23. Cajzl, J.; Peterka, P.; Honzátko, P.; Podrazký, O.; Kamrádek, M.; Aubrecht, J.; Proboštová, J.; Kašík, I. Evaluation of energy transfer coefficients in Tm doped fibers for fiber lasers. Proc. SPIE 2017, 10603. [CrossRef]

24. Eichhorn, M. Numerical Modeling of Tm-Doped Double-Clad Fluoride Fiber Amplifiers. IEEE J. Quantum Electron. 2005, 41, 1574-1581. [CrossRef] 
25. Peterka, P.; Kasik, I.; Dhar, A.; Dussardier, B.; Blanc, W. Theoretical modeling of fiber laser at $810 \mathrm{~nm}$ based on thulium-doped silica fibers with enhanced ${ }^{3} \mathrm{H}_{4}$ level lifetime. Opt. Express 2011, 19, 2773-2781. [CrossRef] [PubMed]

26. Chen, G.X.; Zhang, Q.Y.; Yang, G.F.; Jiang, Z.H. Mid-Infrared Emission Characteristic and Energy Transfer of $\mathrm{Ho}^{3+}$-Doped Tellurite Glass Sensitized by Tm ${ }^{3+}$. J. Fluoresc. 2007, 17, 301-307. [CrossRef] [PubMed]

27. de Camargo, A.S.S.; de Oliveira, S.L.; de Sousa, D.F.; Nunes, L.A.O.; Hewak, D.W. Spectroscopic properties and energy transfer parameters of $\mathrm{Tm}^{3+}$ ions in gallium lanthanum sulfide glass. J. Phys. Condens. Matter 2002, 14, 9495-9505. [CrossRef]

28. Taher, M.; Gebavi, H.; Taccheo, S.; Milanese, D.; Balda, R. Novel approach towards cross-relaxation energy transfer calculation applied on highly thulium doped tellurite glasses. Opt. Express 2011, 19, 26269-26274. [CrossRef] [PubMed]

29. Peterka, P.; Honzatko, P.; Becker, M.; Todorov, F.; Pisarik, M.; Podrazky, O.; Kasik, I. Monolithic Tm-doped fiber laser at $1951 \mathrm{~nm}$ with deep-UV femtosecond-induced FBG pair. IEEE Photonics Technol. Lett. 2013, 25, 1623-1625. [CrossRef]

30. Faure, B.; Blanc, W.; Dussardier, B.; Monnom, G. Improvement of the Tm3+:3H4 level lifetime in silica optical fibers by lowering the local phonon energy. J. Non-Cryst. Solids 2007, 353, 2767-2773. [CrossRef]

31. Blanc, W.; Sebastian, T.L.; Dussardier, B.; Michel, C.; Faure, B.; Ude, M.; Monnom, G. Thulium environment in a silica doped optical fibre. J. Non-Cryst. Solids 2008, 354, 435-439. [CrossRef]

32. Dussardier, B.; Blanc, W.; Peterka, P. Tailoring of the local environment of active ions in rare-earth- and transition-metal-doped optical fibres, and potential applications. In Selected Topics on Optical Fiber Technology; Yasin, M., Harun, S.W., Arof, H., Eds.; InTech: Rijeka, Croatia, 2012.

33. Dennis, M.L.; Duling, I.N., III. Experimental study of sideband generation in femtosecond fiber lasers. IEEE J. Quantum Electron. 1994, 30, 1469. [CrossRef]

34. Smith, N.J.; Blow, K.J.; Andonovic, I. Sideband generation through perturbations to the average soliton model. IEEE J. Lightwave Technol. 1992, 10, 1329. [CrossRef]

35. Nilsson, J.; Clarkson, W.A.; Selvas, R.; Sahu, J.K.; Turner, P.W.; Alam, S.-U.; Grudinin, A.B. High-power wavelength-tunable cladding-pumped rare-earth-doped silica fiber lasers. Opt. Fiber Technol. 2008, 10, 5-30. [CrossRef]

(C) 2018 by the authors. Licensee MDPI, Basel, Switzerland. This article is an open access article distributed under the terms and conditions of the Creative Commons Attribution (CC BY) license (http://creativecommons.org/licenses/by/4.0/). 